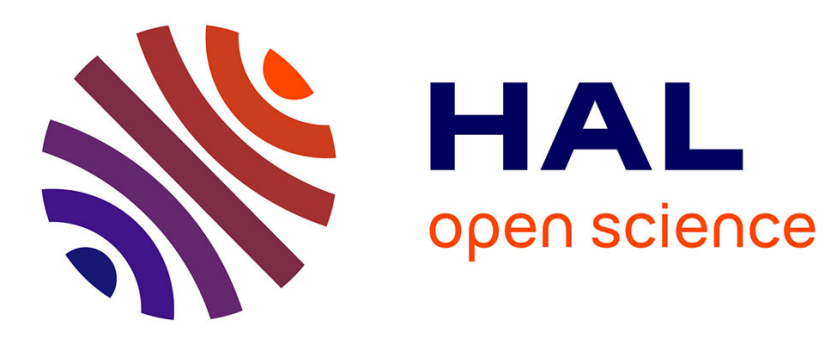

\title{
Harp plucking robotic finger
}

Delphine Chadefaux, Jean-Loic Le Carrou, Marie-Aude Vitrani, Sylvère

Billout, Laurent Quartier

\section{To cite this version:}

Delphine Chadefaux, Jean-Loic Le Carrou, Marie-Aude Vitrani, Sylvère Billout, Laurent Quartier. Harp plucking robotic finger. IEEE/RSJ International Conference on Intelligent Robots and Systems, Oct 2012, Vilamoura, Portugal. 10.1109/IROS.2012.6385720 . hal-01170724

\section{HAL Id: hal-01170724 https://hal.sorbonne-universite.fr/hal-01170724}

Submitted on 2 Jul 2015

HAL is a multi-disciplinary open access archive for the deposit and dissemination of scientific research documents, whether they are published or not. The documents may come from teaching and research institutions in France or abroad, or from public or private research centers.
L'archive ouverte pluridisciplinaire HAL, est destinée au dépôt et à la diffusion de documents scientifiques de niveau recherche, publiés ou non, émanant des établissements d'enseignement et de recherche français ou étrangers, des laboratoires publics ou privés. 


\title{
Harp plucking robotic finger
}

\author{
Delphine Chadefaux, Jean-Loïc Le Carrou, Marie-Aude Vitrani, Sylvère Billout and Laurent Quartier
}

\begin{abstract}
This paper describes results about the development of a repeatable and configurable robotic finger to pluck harp strings. Eventually, this device will be a tool to study string instruments in playing conditions. We used a classical robot with two degrees of freedom enhanced with silicone fingertips. The validation method requires a comparison with a real harpist performance. A specific experimental setup using a high-speed camera combined with an accelerometer was carried out. It provides finger and string trajectories during the whole plucking action and the soundboard vibrations during the string oscillations. A set of vibrational features of these vibrations are then extracted to compare robotic finger to harpist plucking actions. These descriptors have been analyzed on six fingertips of various shapes and hardnesses. Results allow to select the optimal shape and hardness among the silicone fingertips according to vibrational features.
\end{abstract}

\section{INTRODUCTION}

Robots playing musical instruments have been developed under the possibilities of automation and robotics. First straightforward mechanical automatons, musician robots are now able to produce realistic sounds. They can even be compared to real musician. A detailed history and evolution of musician robots are given in [1], [2], [3], [4]. Two particularly striking examples are the Waseda Flutist Robot (WF-4RII) [5] and a violin playing robot [6]. Both are studied in comparison of a real musician's performance. Dealing with acoustical signals, features extracted from timefrequency analyses indicate that produced sounds seem to be realistic. Thus, musician robots can be of great interest to study musical instruments. Indeed, their investigation in playing conditions requires a highly controllable and repeatable excitatory mechanism. Some apparatus were already designed to study wind instruments as blowing machines. Their development began in 1941 [7] and is still in progress to study reed instruments [8], air-jet instruments [9] and brass instruments [10]. Regarding string instruments, the first artificial bow was designed in 1957 [11] to investigate violin family instruments. Mechanical systems have been developed for plucked string instruments. These devices are based on a wire placed around a string and pulled until it breaks. Note that the wire can be automatically [13] or manually pulled [12]. However, these systems are far from the real plucking, especially for the harp. Considering the classical playing technique, the fingertip slips on the string and imposes

D. Chadefaux, JL. Le Carrou and L. Quartier are with LutheriesAcoustique-Musique Team from d'Alembert, UPMC Univ Paris 06, UMR CNRS 7190, Paris, France. jean-loic.le_carrou@upmc.fr

MA. Vitrani is with Institut des Systèmes Intelligents et de Robotique UMR CNRS 7222, Paris, France.

S. Billout is with Institut des Systèmes Intelligents et de Robotique UMR CNRS 7222 and Lutherie-Acoustique-Musique Team from d'Alembert, UPMC Univ Paris 06, UMR CNRS 7190, Paris, France. initial conditions which are a complex mix of displacement, velocity and rotation [14]. Contrary to a wire, a robotic finger could provide these particular initial conditions. The present paper describes results from the development of a robotic finger to pluck the harp strings. As this robot is designed to reproduce the harpist plucking, an evaluation by comparison with harpist's performances is required.

Our paper is organized as follows. First, we describe the harp plucking and the artificial finger we designed.Then, an experiment is setup to measure the artificial finger displacement during the plucking and the soundboard vibration. Hence, a comparison between the artificial finger and harpist plucking action is obtained through trajectories and vibrational data. Finally, we evaluate that one can rely on the designed system in ways to reproduce harpists' plucking gestures.

\section{PLUCKING DESCRIPTION}

In a previous study [14], measurements were performed with ten harpists in several musical contexts. A wellcontrolled experimental setup had been designed to study the harp plucking action. About 150 plucking actions of the 30th string ( $\mathrm{D} b 2$ at a fondamental frenquency of $138.6 \mathrm{~Hz})$ have been analyzed. They were extracted from chord and arpeggio sequences, performed with the annular and the forefinger. The analysis of this database had shown that the motion is performed in the plane perpendicular to the direction of the strings and that it can be decomposed into three sequences [15], [16], [14]. First, the sticking phase (from about $100 \mathrm{~ms}$ to $400 \mathrm{~ms}$ ), when the finger and the string move in parallel to each other at the contact point, $\forall t \in\left[t_{c} ; t_{s}[\right.$. Secondly, the slipping phase (about $3 \mathrm{~ms}$ ), when the string slips on the finger surface with opposite direction $\forall t \in\left[t_{s} ; t_{r}\right]$. At a time denoted $t_{r}$, the string is released and its current characteristics (shape, velocity, ...) turn to be of prime importance on determining the produced sound. It defines, indeed, the initial conditions of the string free oscillations $\forall t>t_{r}$.

The study of these plucking actions show different kind of trajectories, depending mostly on the performer and the technique she / he used. The movement of the harpist's finger can indeed be almost straight as well as really sinuous. Furthermore, a striking observation on the whole panel of plucking action is that it takes place in a square with sides $20 \mathrm{~mm}$ long. Moreover, regarding the finger behavior, $97 \%$ of the evaluated maximum velocities is less than $1.5 \mathrm{~m} / \mathrm{s}$ while $90 \%$ of them is less than $1 \mathrm{~m} / \mathrm{s}$. The force applied by the finger on the 30th string is up to $15 \mathrm{~N}$. Finally, each harpist provides specific but highly reproducible initial 
conditions to the string vibrations. Its displacement, velocity and angular deviation have been measured at the release instant up to $8 \mathrm{~mm}, 5 \mathrm{~m} / \mathrm{s}$ and $80^{\circ}$, respectively.

\section{ROBOTIC FINGER DESCRIPTION}

\section{A. Description}

As the robotic finger is designed to pluck harp strings, it has to be sturdy and at least as repeatable and accurate than a real harpist. Besides, it has to satisfy the specifications defined in Tab. I. They are based on the knowledge of the plucking properties presented Sec. II.

TABLE I

ROBOTIC FINGER SPECIFICATIONS.

\begin{tabular}{|c||c|}
\hline Data & Maximum value \\
\hline Force & $15 \mathrm{~N}$ \\
Area of use & $20 \times 20 \mathrm{~mm}^{2}$ \\
Velocity of the fingertip & $1.5 \mathrm{~m} / \mathrm{s}$ \\
Trajectories duration & $200 \mathrm{~ms}$ \\
\hline
\end{tabular}

The robotic finger designed is presented in Fig. 1. Its base was conceived to be attached to the harp's column, as shown in Fig. 1. As the plucking action takes place in the plane perpendicular to the direction of the strings, the robot is chosen to be planar with two rotational joints. The conception of the yellow-arm in Fig. 1 works toward the achievement of the given force specification. Also, its geometry allows the length comparison of the last two human forefinger phalanxes, i.e. a length of $45 \mathrm{~mm}$.
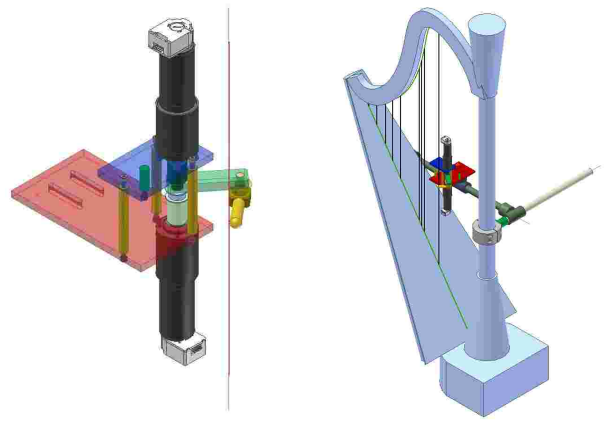

Fig. 1. Artificial finger on its frame (left) and rigidly fixed on the harp's column (right).

As a matter of compactness, both motors are placed at the robot's base. A belt is used to transmit motor's torque to the second joint, as present in Fig. 2. The chosen belt has a length of $177.5 \mathrm{~mm}$, and a thread of $2.5 \mathrm{~mm}$. Considering that the diameter of the pulleys values $17 \mathrm{~mm}$, the spacing is equal to $\frac{L-\pi D}{2}=62.04 \mathrm{~mm}$, ceiling to $62.1 \mathrm{~mm}$. As the harpist finger movement is enclosed in a square area of about $20 \mathrm{~mm}$ side. The robotic finger setup allows the end-effector to follow any trajectory in a $400 \mathrm{~mm}^{2}$. In order to perform the specific force and velocity within this area, the actuation system is based on chain compound of Maxon RE35 motors, associated with Maxon GP 42C reducer and Maxon HEDL 5540 encoder.

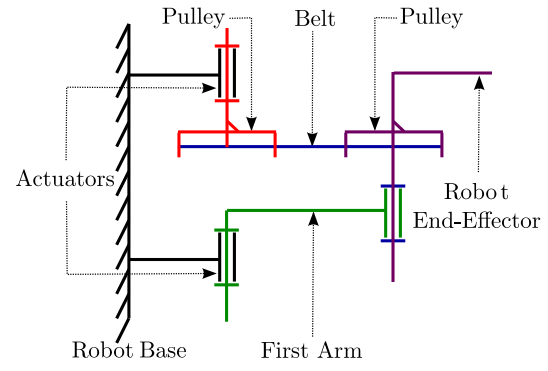

Fig. 2. Robot kinematics

This robot is position-controlled, see [17]. The frequency of this control loop is $1 \mathrm{kHz}$. A graphical user interface allows to define the trajectory the robot has to follow.

It is a classical robot but the musical instrument study context implies some additional constrains. For instance the way it is fixed has to prevent the robot to be prone to the harp vibrations or the great importance of the fingertip shape and material regarding the relevance of the produced finger / string interaction.

\section{B. Fingertip shape and material}

Fingertip shape and material are important aspects on the design. Both define the friction behavior between finger and string. The most suitable material for a robotic finger depends on various properties established by the application, such as friction / adhesion, mechanical properties, durability and suitability for tactile sensing [18], [19]. In touch experiments using a reference textile (normal loads vary between about $0.2 \mathrm{~N}$ to $15 \mathrm{~N}$ ), silicone and the human skin friction coefficients are found to be close [20]. This is why, in our experiment, we chose silicone to mold the pulp of the real finger. As shown in Fig. 3, this piece of silicone is surrounding a bone made of aluminum. The fingertip's size is similar to real human one.

In order to pinpoint the most appropriate parameters for the fingertip, a parametric study, analogous to [21], is carried out. Three shapes and four materials, defined in Tab. II and shown in Fig. 4, were tested. Note that adding filler increases viscosity and hardness, while adding silicone oil dilutes it and decrease those characteristics.

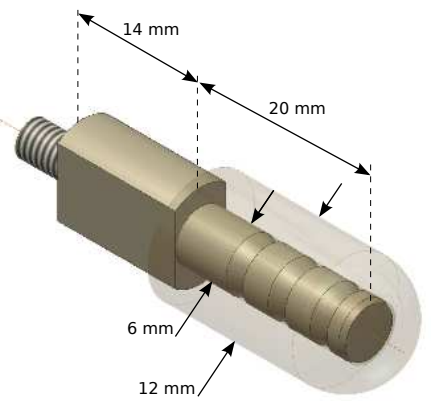

Fig. 3. Description of the Fingertip: bone in aluminum and fingertip in silicone. 


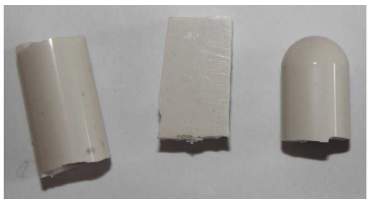

(a) Top view.

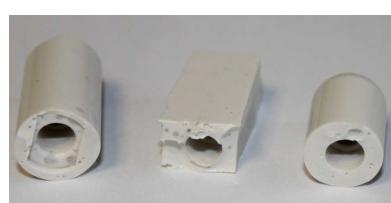

(b) Side view.
Fig. 4. Silicone fingertips of three different shapes: B-C-A

TABLE II

SILICONE FINGERTIPS CHARACTERISTICS.

\begin{tabular}{|c||c|c|}
\hline Notation & Shape & Material \\
\hline A5 & $\begin{array}{c}\text { A: Cylindrical; } \\
\text { round-extremity }\end{array}$ & Silicone $+5 \%$ of filler \\
\hline A15 & $\begin{array}{c}\text { A: Cylindrical; } \\
\text { round-extremity }\end{array}$ & Silicone $+15 \%$ of filler \\
\hline A15O & $\begin{array}{c}\text { A: Cylindrical; } \\
\text { round-extremity }\end{array}$ & Silicone $+15 \%$ of silicone oil \\
\hline A5L & $\begin{array}{c}\text { A: Cylindrical; } \\
\text { round-extremity }\end{array}$ & $\begin{array}{c}\text { Silicone }+5 \% \text { of filler } \\
+ \text { latex skin layer }\end{array}$ \\
\hline B5 & $\begin{array}{c}\text { B: Cylindrical; } \\
\text { float-extremity }\end{array}$ & Silicone $+5 \%$ of filler \\
\hline C5 & C: Plane-parallel & Silicone $+5 \%$ of filler \\
\hline
\end{tabular}

\section{EXPERIMENTAL PROCEDURE}

\section{A. Experimental setup}

In order to evaluate the artificial finger performances in comparison with harpist, a measurement protocol is carried out. It is based on filming simultaneously the finger's distal phalanx and string interaction with a high-speed camera and measuring the soundboard vibrations with an accelerometer glued to the bottom of the studied string. The estimation of the finger and the string trajectories in the plane perpendicular to the direction of the strings is done by tracking markers positioned at strategic places. Concerning harpist's finger, the marker is positioned close to the nail, which is assumed to be rigid and have the same movement as the distal phalanx. The robotic finger's marker is placed at the silicone fingertip's extremity since it is assumed to have the same behavior as the robot end-effector. Regarding the string, marker is glued as close as possible to the plucking position. Markers positions were detected automatically through image processing, using a block-matching algorithm combined with an active contour model [22], [23]. Finally, as the setup has to be the same for harpist and robotic finger which is fixed to the harp (in Fig. 1), the former could not tilt the harp as in an usual musical performance.

\section{B. Measurements protocol}

The general focus of the present study is to provide a robotic finger able to put one harp string into vibrations in the style of a real harpist. For robotic finger evaluation purpose, a harpist has been asked to pluck eight times the 30th string with the right forefinger. The performed movements are presented in Fig. 6. Note that all strings but the plucked one were damped. One over these eight plucking actions has been choose due to its consistency regarding to the whole panel (the grayed one in Fig. 6). The extracted finger

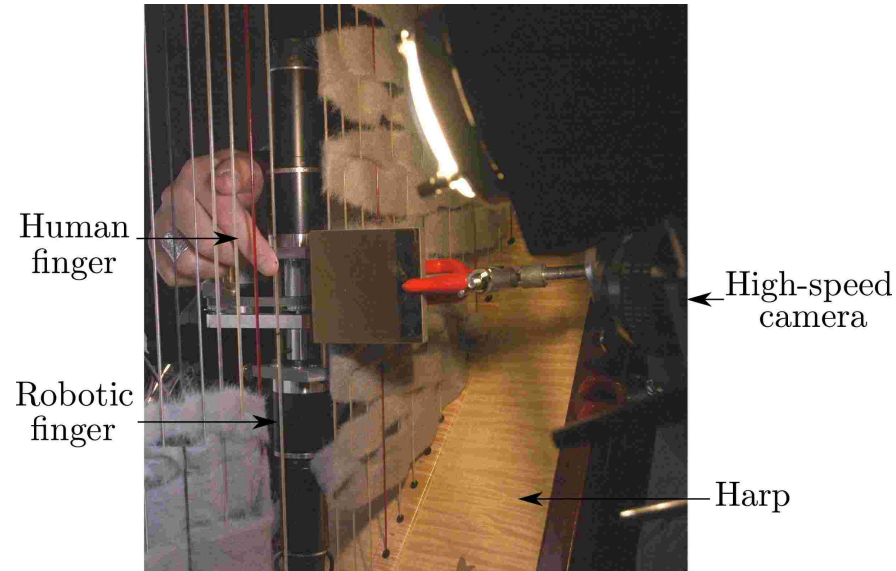

Fig. 5. Experimental setup with human and artificial plucking systems.

trajectory has then been injected as reference to the robotic finger. It executes them with six different silicone fingertips, characteristics of which are presented in Tab. II.

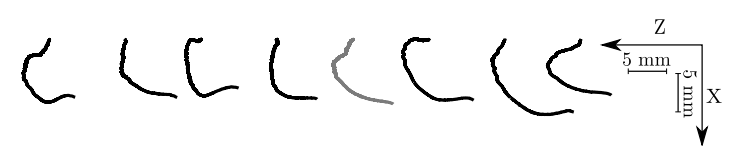

Fig. 6. Harpist forefinger movement during plucking actions. The grayed movement is used as reference for the robot.

\section{RESULTS}

In the following, the robotic finger is evaluated at different steps of the plucking action. First, the repeatability of the robot end-effector is analyzed. Then, the finger's distal phalanx trajectories are compared with the expected ones. Finally, the resulting soundboard vibrations, hence the produced notes, are investigated.

\section{A. Robotic finger repeatability}

Each harpist provides highly reproducible movement to the string she / he plucks [14]. Although it is obvious that a servocontrolled DC-motor driven robot is more repeatable than human finger in no-load conditions, the dynamic time warping algorithm [24] is used to quantify it over eight repetitions of a plucking action: the robotic finger is about 82 times more repeatable than the harpist. Thus, the repeatability condition is clearly fulfill.

\section{B. Plucking action reliability}

In order to evaluate the relevance of each silicone fingertip, the measured phalanx trajectories are compared to the robot end-effector and the reference ones in Fig. 7. Let us consider the reliability of the robotic finger trajectory compared with the human finger's one. The reference trajectory is wellreproduced by the robotic finger. However, a slight deviation appears at the end of the sticking phase and reaches its maximum value at the beginning of the slipping phase $t_{s}$. According to [14], it means that the higher the force applied to the finger by the string is, the more the deviation from the 
reference is important. Silicone fingertips trajectories agree with the reference during the first half of the plucking action. Then, the force applied by the string on the fingertip reaches important values and the local deformation of silicone induced deviation (Fig. 7). For instance, the fingertip A15O which has the lowest hardness shows the most important difference with harpist finger trajectory. Fingertip A15 and A5L which are harder than the others are closer to the latter until the slipping phase.

Regarding the reference, characteristic plucking phases defined Sec. II last $326.6 \mathrm{~ms}$ and $2.8 \mathrm{~ms}$ for the sticking and slipping phase, respectively. Tab. III-a) gives those durations for each silicone fingertip, denoting $\Delta \Phi_{c}$ and $\Delta \Phi_{s}$ the sticking and the slipping phases duration, respectively. Sticking phase lasts about $25 \%$ longer than expected without outstanding differences between fingertips. On the other hand, the slipping duration errors are ranged from $7 \%$ to $186 \%$. These significant differences are most likely explained by the various fingertip mechanical properties (friction coefficient, hardness, ...). As a consequence, the displacement and the velocity of the string at the release instant will be changed, implying variations in the spectral content.

The maximal force applied by the finger to the string denoted $F_{\max }$ in Tab. III-b) is computed as described by the classical plucked string theory [25]. The estimation of $F_{\max }$ for the six fingertips is good in relation to the value measured on the harpist plucking (about $8.0 \mathrm{~N}$ ) with an average error of $12 \pm 3 \%$, where the reported uncertainty represents a $95 \%$ confidence interval. The maximal force, directly induced by the friction coefficient, is related to the dynamic of the produced vibrations. The waveforms of each plucking action presented in Fig. 8 illustrate this remark. For instance, A15O and A5L fingertips convey to the lowest measured maximal forces (5.6 and 6.6, respectively) and clearly the lowest vibrational magnitude in Fig. 8.

\section{Initial conditions of the string vibrations}

The conditions of the string at the release instant define its free oscillations [25], i.e. the way the soundboard will vibrate and the characteristics of the produced sound. Thus, descriptors of the initial conditions of the vibration phase are considered. They are presented in Tab. III-b). The initial displacement of the string at the release instant denoted $\mathrm{D}$ is $6.5 \mathrm{~mm}$ and ranged from $1.0 \mathrm{~mm}$ to $5.7 \mathrm{~mm}$ for the reference and the silicone fingertips, respectively. As previously mentioned, this descriptor is related to the slipping duration. Indeed, it is straightforward that the more the latter is long, the closer the string returns towards its rest position and, hence, the less the initial string displacement is.

The initial velocity of the string at the release instant is denoted V in Tab. III-b). As for D, the order of magnitude of $\mathrm{V}$ is relevant for the robotic finger with A-shaped fingertip and middle or high hardness. Inconsistency in this descriptor are due to an irrelevant friction coefficient. Indeed, the more deviated maximal force and slipping duration values are estimated for A15O, A5L and C5 silicone fingertips, which also provide the more erroneous velocity values.
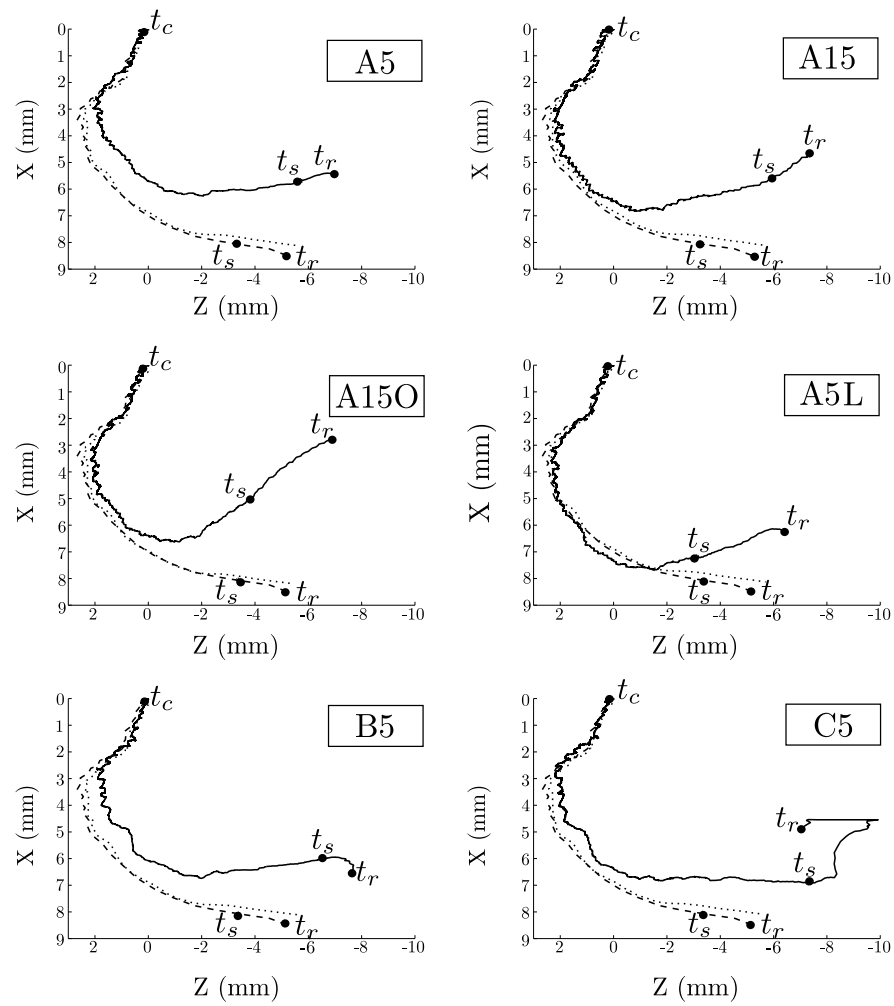

Fig. 7. Comparison of each silicone fingertips trajectory with robotic finger and reference trajectories. Plain line: Silicone fingertip. Dotted line: Robotic finger. Dashed line: Harpist finger trajectory which is defined as reference

\section{Soundboard vibrations}

To enhance the study, the analysis of the produced sound is essential. It will be useful to pinpoint the effect of the highlighted variability between reference and resulting initial conditions of the string vibrations on the soundboard vibrations. For this purpose, the waveforms of each analyzed plucking action are shown in Fig. 8.

Besides the already mentioned variations in the silicone fingertip's waveforms magnitude, we observe shapes differences between signals. They seem to be related to the fingertip's geometry. Indeed, waveforms obtain using Ashaped fingertips show a similar wave pattern just after the maximal magnitude is reached, while the one convey by $\mathrm{B}$ and C-shaped fingertips have their own particular shapes. Considering vibrations magnitude, the C5 fingertip is the better of the six used. However, regarding the waveform, A15 and A5 fingertips are the closest to the harpist reference.

In order to highlight the better properties to provide to a silicone fingertip, we extract and compare characteristic features of these signals [26]. They are presented in Tab. IIIc), and defined as follow:

- $\mathrm{P}_{i}$ measures the amplitude of the ith peak of the spectrum, in decibel;

- the spectral centroid measures the barycenter of the spectrum: $\mu=\int_{0}^{N} \tilde{X} \cdot P(\tilde{X}) \delta \tilde{X}$, in Hertz;

- $\sigma^{2}$ is the spread of the spectrum around its barycenter: 

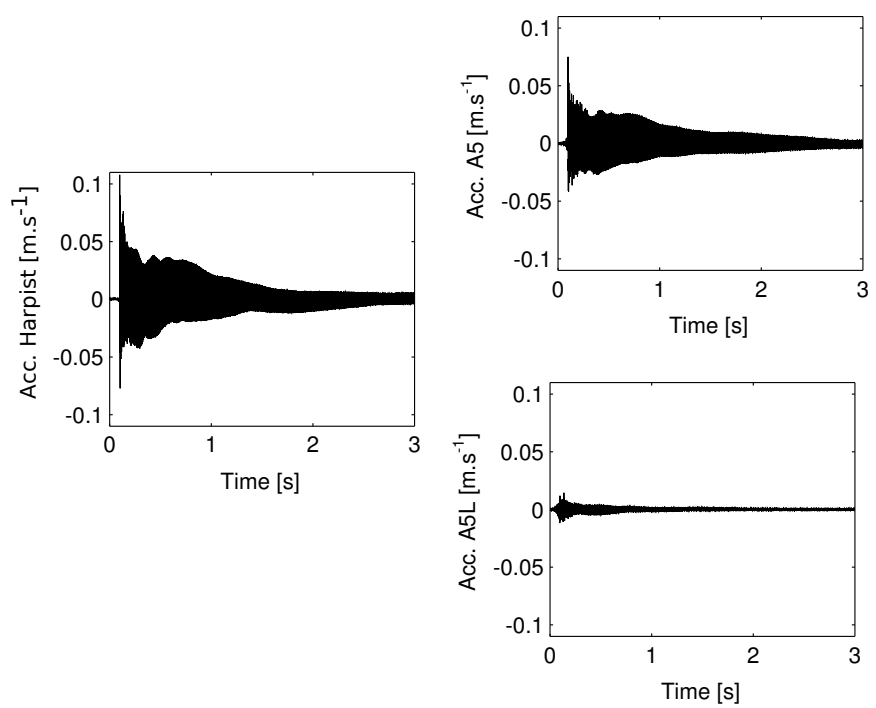
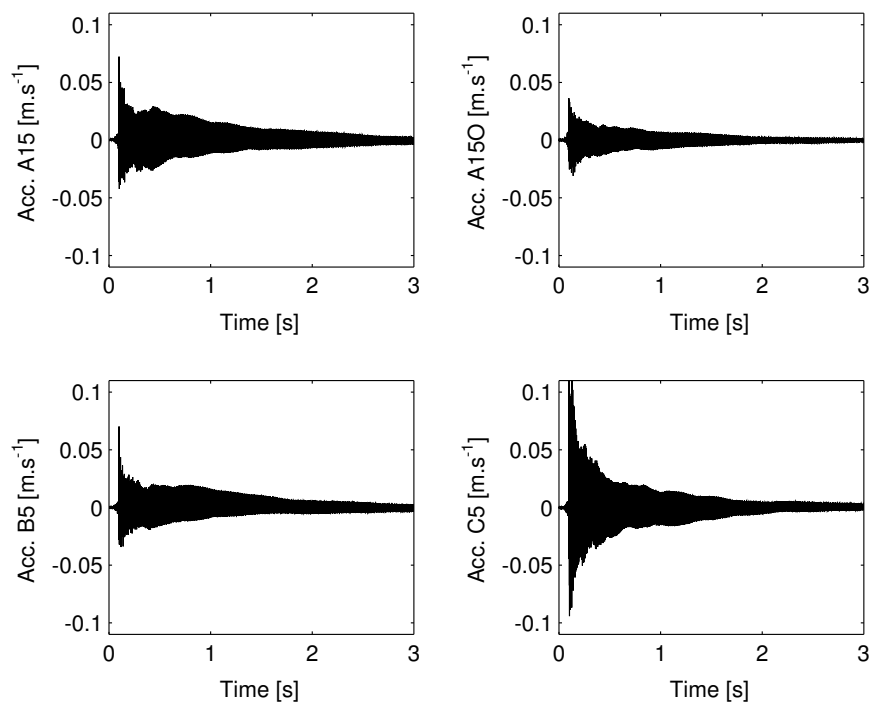

Fig. 8. Accelerometer's signals measured on isolated $\mathrm{Db} 2(138.6 \mathrm{~Hz})$ performed by the reference and the robotic finger with each silicone fingertip at the bottom of the 30 th string.

$\sigma^{2}=\int_{0}^{N}(\tilde{X}-\mu)^{2} \cdot P(\tilde{X}) \delta \tilde{X}$, in Hertz;

- the skewness measures the asymmetry of the spectrum energetic distribution around its barycenter: $S K=\int_{0}^{N}(\tilde{X}-\mu)^{3} \cdot P(\tilde{X}) \delta \tilde{X}$, dimensionless;

- and the kurtosis measures the flatness of the spectrum energetic distribution around its barycenter:

$K=\int_{0}^{N}(\tilde{X}-\mu)^{2} \cdot P(\tilde{X}) \delta \tilde{X}$, dimensionless;

denoting $\tilde{X}$ the spectrum of the observed soundboard vibrations of length $\mathrm{N}$ and $P(\tilde{X})$ the probability to observe $\tilde{X}$.

According to results presented in Tab. III-c), notes produced by the 6 silicone fingertips are relevant compared to the reference. The error averaged on all vibrations descriptors is ranged from $9.9 \%$ to $41.8 \%$. Remarque that the amplitude and ratio of the spectral peaks are globally wellreproduced while spectral centroid and spectral spread imply error percentage up to $53 \%$. It means that, excepted for the A5L finger, the acoustical level and the spectral balance are approximately well-reproduced, but not always the spectral shape.

Moreover, spectrograms of each plucking action have been computed and presented in Fig. 9. Unlike the harpist one, signals performed by the robotic finger do not contain the $3^{\text {rd }}$ and the $6^{\text {st }}$ harmonics. This difference is due to the plucking position. Indeed, as the robot was plucking exactly the string at the third of its length, the harpist's finger position on the string was prone to slight variations. Furthermore, the transient part, which is essential at a sound perception level, is clearly different from one spectrogram to another. Transient obtain with A5, A15 and C5 fingertips are the closest to the one produced by the real harpist. Again, this phenomenon is the consequence of the various silicone friction coefficients. Finally, an intuitive result is shown: signals resulting from sharp fingertips (B and $\mathrm{C}$ shapes) own more energy in high-frequencies than those resulting from smooth fingertips (A-shape) which are closer to the reference spectral energy distribution. Then, adding a glove on the silicone fingertip implies a 30-times reduction of the energy in the signal. Furthermore, considering a same shape, the less the silicone is hard, the lower the sound radiated energy is.

Finally, according to descriptors presented in Tab. III in its entirety combined with spectrograms, the isolated notes produced by a part of the set of silicone fingertips is suitable for a harp sound. The silicone fingertip which matches up better with the harpist performance is A-shaped and made of silicone with $5 \%$ of filler, with an average error percentage of $9.9 \%$ regarding to the reference.

\section{CONCLUSION}

In this paper we presented results about the development of a repeatable and configurable artificial finger able to pluck a string, especially using a classical harp playing technique. The chosen robot is planar with two rotational joints. It is enhanced by a silicone fingertip. To this end, six silicone fingertips differing on shape and hardness have been molded. The evaluation of the robotic finger is carried out by comparison of its performances with those of a harpist. Using a well-controlled measurement protocol based on the evaluation of the finger / string trajectories along the plucking action and the measurement of the soundboard vibrations, both plucking action and soundboard vibrations are compared by analyzing plucking action and vibrational features.

The robotic finger mostly fulfill repeatability and accuracy objectives relative to the harpist. Concerning the silicone fingertip, one particular shape appears to be relevant over the three tested: cylindrical with round-fingertip. Besides, the silicone's hardness is of great importance. It implies a more or less important deformation of the fingertip which has an influence on the finger / string friction and the initial conditions of the string free oscillations. According 


\section{CONFIDENTIAL. Limited circulation. For review only.}

TABLE III

CLASSIFICATION OF THE SILICONE FINGERTIPS ACCORDING TO CHARACTERISTIC DESCRIPTORS OF THE PLUCKING ACTION. THE GRAYED-COLORED BOXES CORRESPOND TO THE GLOBAL BETTER FINGERTIPS. THE BOLD VALUES CORRESPOND TO THE CLOSEST SILICONE FINGERTIP TO THE REFERENCE FOR THE CONSIDERED DESCRIPTOR.

\begin{tabular}{|c|c|c|c|c|c|c|c|}
\hline \multicolumn{8}{|c|}{ a) Plucking action characteristics } \\
\hline Descriptor & Reference & A5 & A15 & $\mathrm{A} 15 \mathrm{O}$ & A5L & B5 & C5 \\
\hline$\Delta \Phi_{c}(\mathrm{~ms})$ & 326.6 & 409.4 & 408.7 & 403.5 & 402.2 & 409.2 & 409.2 \\
\hline$\Delta \Phi_{s}(\mathrm{~ms})$ & 2.8 & 2.4 & 2.6 & 5.7 & 8.0 & 3.8 & 4.3 \\
\hline $\mathrm{F}_{\max }(\mathrm{N})$ & 8.0 & 7.1 & 7.1 & 5.6 & 6.6 & 7.6 & 9.8 \\
\hline \multicolumn{8}{|c|}{ b) Release instant characteristics } \\
\hline Descriptor & Reference & A5 & A15 & $\mathrm{A} 15 \mathrm{O}$ & $\mathrm{A} 5 \mathrm{~L}$ & B5 & $\mathrm{C} 5$ \\
\hline $\mathrm{D}(\mathrm{mm})$ & 6.5 & 5.7 & 5.1 & 3.3 & 2.2 & 4.7 & 1.0 \\
\hline $\mathrm{V}(m / s)$ & 1.2 & 1.19 & 1.19 & 0.68 & 0.92 & 2.3 & 0.58 \\
\hline \multicolumn{8}{|c|}{ c) Spectral soundboard vibrations descriptors } \\
\hline Descriptor & Reference & A5 & A15 & A15O & A5L & B5 & $\mathrm{C5}$ \\
\hline $\mathrm{P}_{1}(\mathrm{~dB})$ & 68 & 64 & 63 & 51 & 44 & 64 & 60 \\
\hline $\mathrm{P}_{1} / \mathrm{P}_{2}(\mathrm{~dB})$ & 1.1 & 1.0 & 1.0 & 1.1 & 0.94 & 1.1 & 0.92 \\
\hline $\mathrm{P}_{2} / \mathrm{P}_{4}(\mathrm{~dB})$ & 0.91 & 1.0 & 0.98 & 0.77 & 1.0 & 1.0 & 1.0 \\
\hline$\mu(\mathrm{Hz})$ & 722 & 673 & 900 & 1017 & 745 & 831 & 1106 \\
\hline$\sigma^{2}(\mathrm{kHz})$ & 534 & 527 & 1117 & 1081 & 817 & 975 & 1008 \\
\hline SK (-) & 2.4 & 2.6 & 2.0 & 1.8 & 2.5 & 2.1 & 1.6 \\
\hline K (-) & 10.5 & 11.9 & 6.7 & 6.0 & 10.0 & 7.6 & 5.5 \\
\hline \multicolumn{8}{|c|}{ d) Fingertip classification } \\
\hline \multicolumn{2}{|c|}{$\begin{array}{c}\text { Silicone fingertip } \\
\end{array}$} & A5 & A15 & B5 & A5L & $\mathrm{C} 5$ & A15O \\
\hline Average errc & ed to the reference & $\mathbf{9 . 9} \%$ & $23.1 \%$ & $28.2 \%$ & $36.7 \%$ & $41.5 \%$ & $41.8 \%$ \\
\hline
\end{tabular}
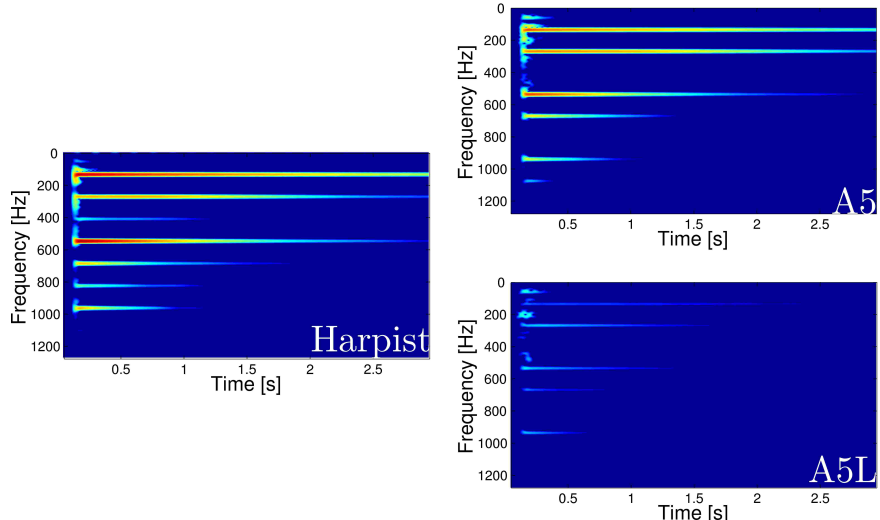
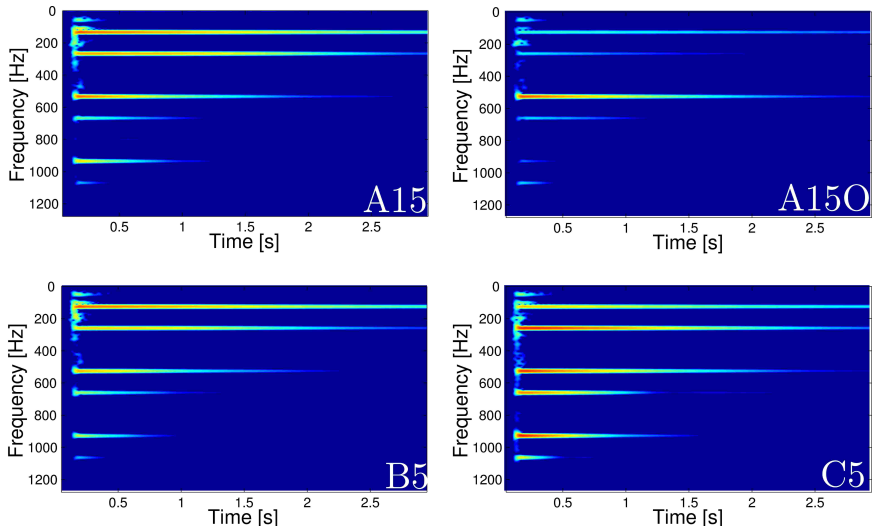

Fig. 9. Spectrograms computed on isolated Db2 $(138.6 \mathrm{~Hz})$ performed by the reference and the robotic finger with each silicone fingertip. Pictures are drawn in $\mathrm{dB}$ using a $70 \mathrm{~dB}$ dynamic.

to vibrationally-relevant descriptors of the soundboard vibrations, a middle or high hardness is relevant.

Further work will be carried out to investigate the fingertip instrumentation. For instance, strain gauges will be set up to measure the force applied on it. This will be helpful to provide informations about the plucking process to the robotic finger controller. It will also be interesting to mold fingertips with other material in order to achieve a thorough study of the finger / string friction characteristic.

Finally this is the first step to a repeatable and configurable excitation system to study string instruments behavior in playing conditions or to point out the influence of musical gesture parameters on the radiated sound.

\section{ACKNOWLEDGMENTS}

The authors acknowledge the harpist who participated in this study: Sandie Le Conte, Wael Bachta for his help during the finger robot setup and Maxime Harazi for his help during the measurements.

\section{REFERENCES}

[1] T.M. Sobh, B. Wang and K.W. Coble, Experimental robot musicians, Journal of Intelligent and Robotic Systems, Vol. 38, 2003, pp. 197-212

[2] A. Kapur, A history of robotic musical instruments, Proceedings of the International Computer Music Conference, Barcelona, Spain, 2005

[3] M. Kajitani, Development of musician robots in Japan, Proceedings of the Australian Conference on Robotics and Automation, Brisbane, Australia, 1999

[4] K. Petersen, J. Solis and A. Takanishi, Musical-based interaction system for the waseda flutist robot - Implementation of the visual tracking interaction module, Autonomous Robots, Vol. 28(4), 2010, pp. $471-488$

[5] J. Solis, K Chida, K Taniguchi, S.M. Hashimoto, K. Suefuji and A. Takanishi, The waseda flutist robot WF-4RII in comparison with a professional flutist, Computer Music Journal, Vol. 30(4), 2006, pp. 12-27 
[6] K. Shibuya, S. Matsuda and A. Takahara, Toward developing a violin playing robot - Bowing by anthropomorphic robot arm and sound analysis, IEEE International Conference on Robot \& Human Interactive Communication, Jeju, Korea, 2007

[7] C.S. McGinnis and C. Gallagher, The mode of vibration of a clarinet reed, J. Acoust. Soc. Am, vol. 12, 1941, pp 529-531.

[8] D. Ferrand and C. Vergez, Blowing machine for wind musical instrument: toward a real-time control of the blowing pressure, 16th IEEE Mediterranean Conference on Control and Automation, Ajaccio, France, 2008, pp. 1562-1567

[9] D. Ferrand, C. Vergez,B. Fabre,F. Blanc, High-precision regulation of a pressure controlled artificial mouth: the case of recorder-like musical instruments, Acustica united with Acta Acustica Vol. 96, 2010, pp. 700-711.

[10] J. Gilbert, S. Ponthus and J-F Petiot, Artificial buzzing lips and brass instruments: experimental results, J. Acoust. Soc. Am, vol. 104(3), 1998, pp 1627-1632.

[11] F.A. Saunders, The mechanical action of violins, J. Acoust. Soc. Am, vol. 9(2), 1937, pp 81-98.

[12] J. Woodhouse, Plucked guitar transients: comparison of measurements and synthesis, Acta Acustica united with Acustica, vol. 90, 2004, pp 945-965.

[13] T. Smit, F. Turckheim and R. Mores, A highly accurate plucking mechanism for acoustical measurements of string instruments, $J$. Acoust. Soc. Am, vol. 127(5), 2010, pp EL222-EL226.

[14] D. Chadefaux, JL. Le Carrou, B. Fabre and L. Daudet, Experimentallybased description of harp plucking, J. Acoust. Soc. Am, vol. 131(1), 2012, pp 844-855.

[15] J-L. Le Carrou, F Gautier, F Kerjan and J Gilbert, "The string-finger interaction in the concert harp", In proceedings of ISMA, Barcelone, (2007).

[16] D. Chadefaux, J-L. Le Carrou, B. Fabre, L. Daudet, L. Quartier, "Experimental study of the plucking of the concert harp", In proceedings of ISMA, Sydney, Katoomba, ISBN 978-0-646-54052-8, (2010).

[17] W. Khalil and E. Dombre, "Modeling, Identification \& control of robots", Herms Penton, ISBN-10: 190399666X, ISBN-13: 9781903996669, 2002.

[18] M.R. Cutkosky, J.M. Jourdain and P.K. Wright, Skin Materials for robotic fingers, IEEE International Conference on Robotics and Automation, 1987, pp. 1649-1653.

[19] F. Shao, T.H.C. Childs and B. Henson, Developing and artificial fingertip with human friction properties, Tribology international, vol. 42, 2009, pp 1575-1581.

[20] S. Derler, U. Schrade and L-C. Gerhardt, Tribology of human skin and mechanical skin equivalents in contact with textiles, Wear, vol. 263, 2007, pp 1112-1116.

[21] H-Y. Han, A. Shimada and S. Kawamura, Analysis of Friction on Human Fingers and design of artificial fingers, IEEE International Conference on Robotics and Automation, Minneapolis, US, 1996, pp. 3061-3066.

[22] S.A. El-Azim, "An efficient object tracking technique using blockmatching algorithm", Radio Science Nineteenth National Conference of the Proceedings of NRSC Alexandria, Egypt, 427-433, 2002.

[23] T.F. Chan, L.A. Vese, "Active contours without edges", IEEE Transactions on image processing, Vol. 10, no 2, 266-277, 2001.

[24] H. Sakoe, S. Chiba, Dynamic programming algorithm optimization for spoken word recognition, IEEE Transactions on Acoustics, Speech and Signal Processing, Vol. 26, 1978, pp. 43-49.

[25] N. H. Fletcher and T. D. Rossing, "The Physics of Musical Instruments", 2nd ed., 756 pages, Springer, New York, 1998.

[26] G. Peeters, B. Giordano, P. Susini, N. Misdariis, and St. McAdams, "The Timbre Toolbox: Audio descriptors of musical signals", J. Acoust. Soc. Am, vol. 130(5), 2011, pp 2902-2916. 